\title{
Análise da Instituição do Serviço de Ergonomia em um Frigorífico: Um Estudo Quanti-Qualitativo
}

\author{
Jeniffer Sauthier Alves, ${ }^{1}$ Maria Amélia Bagatini, ${ }^{2}$ Tatiana Cecagno Galvan ${ }^{1}$
}

\begin{abstract}
RESUMO
Objetivo: Analisar os dados de turnover, absenteísmo e afastamentos do trabalho, e compará-los pré e pós-introdução do serviço de ergonomia na empresa. Também objetivou-se analisar a percepção de operadores e gestores referente ao serviço de ergonomia. Método: A pesquisa caracterizou-se como observacional de caráter retrospectivo e experimental de cunho transversal, tendo sido analisados dados da empresa e a aplicação de um questionário a 129 colaboradores. As análises estatísticas foram realizadas no programa SPSS versão 8.0 e $p$ significativo quando menor que 0,05 . Resultados: Ao analisar o período avaliado, não se constatou significância da redução do absenteísmo, turnover e afastamentos do trabalho no período pré e pós-instituição do serviço de ergonomia. Quanto à análise dos questionários percebeu-se significância estatística na relação entre a necessidade da ergonomia na empresa $x$ valorização, necessidade da ergonomia na empresa $x$ segurança, entre a procura do ergonomista $x$ solução de problemas, adaptação percebida $x$ facilitação do trabalho seu ou do colega, percepção de mudança $x$ valorização e percepção de mudança $x$ segurança. Conclusão: Não houve significância estatística na redução do absenteísmo, turnover e afastamentos após adotado o serviço de ergonomia, porém os índices não aumentaram mesmo com o aumento da produtividade e número de colaboradores. Também se conclui que independentemente da hierarquia os trabalhadores percebem a importância, conhecem e por meio de sua opinião demonstraram satisfação com o serviço da ergonomia. Sugere-se novos estudos em empresas com maior número amostral, além de aprofundar os motivos de afastamentos para evitá-los.
\end{abstract}

Palavras-chave: Ergonomia. Fisioterapia. Reorganização de recursos humanos. Licença médica e absenteísmo.

\section{NSTITUTION ANALYSIS OF THE ERGONOMY SERVICE IN A FRIGORIFIC:} A QUANTITATIVE-QUALITATIVE STUDY

\section{ABSTRACT}

Goal: To analyze the data of turnover, absenteeism and leave from work, and compare them before and after implementation of the ergonomics service in the company. It also aimed to analyze the perception of operators and managers regarding the ergonomics service. Method: The research was characterized as observational with a retrospective and experimental character of a transversal character, data from the company and the application of a questionnaire to 129 employees were analyzed. Statistical analyzes were performed using SPSS version 8.0 and significant $p$ when less than 0.05 . Results: When analyzing the period evaluated, there was no significant reduction in absenteeism, turnover and leave from work in the period before and after the ergonomics service was implemented. Regarding the analysis of the questionnaires, statistical significance was perceived in the relationship between the need for ergonomics in the company $x$ valuation, the need for ergonomics in the company $x$ security, between the search for the ergonomist $x$ problem solving, perceived adaptation $x$ facilitating your or your colleague's work, perception of change $x$ valuation and perception of change $x$ security. Conclusion: There was no statistical significance in reducing absenteeism, turnover and leave after the ergonomics service was implemented, but the rates did not increase even with the increase in productivity and number of employees. It is also concluded that regardless of the hierarchy, the workers perceive the importance, know and through their opinion demonstrated satisfaction with the service of ergonomics. New studies are suggested in companies with a larger sample size, in addition to deepening the reasons for leave to avoid them.

Keywords: Ergonomics. Physical therapy specialty. Personnel turnover. Sick leave and absenteeism.

\footnotetext{
Centro Universitário Cenecista de Osório - Osório/RS, Brasil.

${ }^{2}$ Autora correspondente. Centro Universitário Cenecista de Osório - Osório/RS, Brasil. RS 407, Bairro Santo Antônio, Capão da Canoa, 95555-000/Rio Grande do Sul-Brasil. http://lattes.cnpq.br/9752318976629101. https://orcid.org/0000-0002-5694-8621. memibagatini@gmail.com
} 


\section{INTRODUÇÃO}

Na década de 90 do século 20 ocorreu a expansão da economia brasileira, estimulando inúmeras empresas a se tornarem mais competitivas e profissionais. Por consequência, houve a introdução de amplas escalas de produção, muitas vezes sem o emprego de instrumentos apropriados para execução do trabalho, que resultaram no crescimento das doenças ocupacionais (RIBEIRO, 2017). O mesmo ocorreu no setor alimentício, e quando se fala de empresas do ramo frigorífico, deve-se considerar que para a realização da maior parte das tarefas de produção é necessário empenhar elevada frequência de movimentos manuais, favorecendo a incidência de distúrbios musculoesqueléticos. Esse fator é agravado quando associado à posição estática, principalmente nas lesões de membros superiores (BAIXINHO et al., 2016).

Quando presentes, estas desordens ocupacionais podem ser estabelecidas como lesões que advêm de traumas cumulativos decorrentes da atividade laboral. Possuem evolução lenta e gradativa, sendo resultante do desequilíbrio entre a habilidade e a capacidade da musculatura de contrair e realizar movimentos rápidos e contínuos (CARVALHO et al., 2016). Existem, no entanto, outros pontos críticos passíveis de agravar a saúde e segurança do trabalhador deste ramo, por exemplo, as questões ambientais (temperatura, ruídos, maquinário, iluminação e qualidade do ar) (TEIXEIRA, 2017), questões organizacionais (pausas, rodízio de funções, gestão de pessoas), o estado das ferramentas utilizadas e a sua disposição (SOUZA et al., 2019). Neste cenário, visando a reduzir custos com desperdício, retrabalho e afastamentos, atualmente entre os principais itens que recebem atenção dos gestores encontram-se as condições de saúde e segurança no trabalho (SANTIAGO et al., 2017).

No Brasil o meio frigorífico desencadeou tamanhos prejuízos na saúde e segurança dos trabalhadores que com o objetivo de prevenção foi elaborada e efetivada pelo governo uma Norma Regulamentadora (NR) específica para o setor, chamada de Norma Regulamentadora número 36 (NR 36), juntamente com um manual de aplicação para facilitar o entendimento das empresas e profissionais da área. A NR 36, juntamente com a Norma Regulamentadora 17 (NR 17), buscam prevenir as condições de saúde e segurança do trabalhador, incluindo a ergonomia como agente de mudança (MTE, 2013, 1978).

A ergonomia do trabalho é um meio eficaz para prevenir a ocorrência destas desordens, por meio da adaptação do trabalho ao homem (NASCIMENTO et al., 2019). Deste modo, tornou-se uma estratégia para as empresas que buscam aderir a táticas que lhes possibilitem garantir a produtividade considerando a saúde do trabalhador e a integridade ambiental (RIGOTTO, 2018).

Além disso, o fato de a empresa cuidar da saúde, segurança e bem-estar do colaborador em seu ambiente de trabalho, também vem sendo tratado como uma estratégia comercial, principalmente no que se refere à exportação dos produtos alimentícios, uma vez que a empresa poderá sofrer sanções econômicas caso seja identificado que as condições de trabalho sejam danosas ao trabalhador. Além disso, a ergonomia e a segurança do trabalho também contribuem para o bem-estar e segurança do colaborador, que repercute na redução de absenteísmo e por consequência aumenta a produtividade (BAIXINHO et al., 2016).

Outro fator que impacta positivamente na produtividade é a inserção de profissionais da saúde no ambiente industrial, como o fisioterapeuta. Entre as atribuições do fisioterapeuta destaca-se a promoção da qualidade de vida no trabalho, prevenir lesões musculoesqueléticas, melhorar o desempenho do colaborador em sua função, aumentando a produtividade sem prejudicar sua saúde (HURTADO; VÉRAS, 2015).

Deste modo a comparação dos dados pré e pós-estabelecimento do serviço de ergonomia permite avaliar se ele está sendo efetivo e se está adequado às necessidades atuais da empresa. Já a análise da percepção de toda a hierarquia sobre o serviço de ergonomia permite avaliar como ela se sente em relação ao serviço ergonômico e se as adaptações realizadas na empresa foram realmente benéficas aos colaboradores.

Sabendo ainda da importância da saúde, segurança do trabalhador e da economia da empresa, este estudo teve como objetivo analisar os dados de turnover, absenteísmo e afastamentos do trabalho, e compará-los pré e pós-instalação do serviço de ergonomia na empresa. Também objetivou-se analisar a percepção de operadores e gestores referente ao serviço de ergonomia.

\section{METODOLOGIA}

Essa pesquisa foi aprovada pelo Comitê de Ética, conforme parecer de apreciação ética número 19792619.2.0000.5591. A pesquisa caracterizou-se como quantitativa de caráter observacional retrospectivo, quando foram analisados dados já coletados pela empresa, referentes à turnover, absenteísmo e afasta- 
mentos do trabalho no período de julho de 2015 a junho de 2019. Também foi solicitada informação sobre o mês e ano em que se iniciou o serviço de ergonomia na empresa, ou seja, janeiro de 2017. Para obtenção destes dados contatou-se o Serviço de Recursos Humanos (RH) e o Serviço Especializado de Segurança e Medicina do Trabalho (SESMT) por meio de e-mails que foram respondidos no período de 30 dias.

Outra característica deste estudo é ser qualitativo de caráter experimental transversal, no qual toda a hierarquia da empresa foi convidada a responder um sucinto questionário referente ao serviço de ergonomia prestado na unidade. Todos os trabalhadores foram convidados a participar (204 no total) por meio de fôlderes fixados na empresa e também por comunicações orais formais e informais. Para identificar qual a amostra necessária para se tornar estatisticamente relevante foi realizado cálculo amostral. Para tanto utilizou-se população do estudo igual a 204 colaboradores, 95\% de nível de confiança e 5\% de margem de erro, resultando em um valor amostral correspondente a 134 colaboradores.

A coleta de dados ocorreu dentro das dependências da unidade da empresa, conforme autorização do Termo de Anuência, durante cinco dias, nos turnos da manhã e tarde (período produtivo da empresa), possibilitando que todos os trabalhadores tivessem acesso aos avaliadores. Os colaboradores foram abordados antes e depois de registrarem o ponto no início de sua jornada de trabalho, no intervalo de café da manhã e do almoço. Antes de apresentar-lhes os questionários foi solicitado que lessem e assinassem o Termo de Consentimento Livre e Esclarecido (TCLE), recebendo uma via do documento caso aceitasse participar deste estudo. Um total de 129 trabaIhadores $(63,23 \%)$ aceitaram participar.

O estudo obteve amostragem probabilística, aleatória simples sem repetição. Foram estabelecidos como critérios de inclusão os seguintes aspectos: dados de turnover, afastamentos do trabalho e absenteísmo alusivos aos últimos quatro anos; colaboradores de todos os setores do frigorífico e proprietários da empresa. E para exclusão: dados incompletos referentes ao turnover, absenteísmo e afastamento; dados alusivos a 2014 e anos anteriores ou posteriores a junho de 2019. Os dados apresentados nos resultados estão expressos por ano, em que o Ano 1 se refere ao período de julho de 2015 a junho de 2016; o Ano 2 de julho de 2016 a junho de 2017; Ano 3 de julho de 2017 a junho de 2018 e o Ano 4 de julho de 2018 a junho de 2019. Todas as figuras e tabelas incluídas neste estudo seguem a mesma representatividade.
Inicialmente, após retorno da empresa com as informações solicitadas por e-mail, foi executada a tabulação e análise estatística comparativa entre os dados pré e pós-serviço de ergonomia. O mesmo ocorreu após todos os questionários serem preenchidos. Ambas as tabulações e análises estatísticas ocorreram por meio do programa SPSS versão 8.0 para $p$ significativo quando menor que 0,05 , por intermédio do teste de qui-quadrado de Pearson. Os dados quantitativos estão apresentados por média, mediana e porcentagem, dependendo de sua distribuição, e os quantitativos estão expressos por comparações.

\section{RESULTADOS}

A indústria objeto deste estudo trata-se de uma empresa frigorífica localizada no Sul do Brasil, que possui atividades de abate, processamento e expedição, com suporte de SESMT composto por técnico de segurança do trabalho em caráter celetista, engenheiro de segurança, fisioterapeuta, fonoaudióloga e ergonomista por meio de equipes terceirizadas. $\mathrm{O} \mathrm{RH}$ é composto por um analista de recursos humanos. Também possui setor administrativo, de manutenção, lavanderia, refeitório, auditório e sala de descanso. Conta com um total de 204 colaboradores diretos. Todos foram convidados a participar da entrevista e 129 destes aceitaram, observando-se que nenhum questionário foi excluído.

\section{Análise do banco de dados da empresa}

Todos os dados solicitados para a empresa foram enviados aos pesquisadores e foram tabulados, originando a Tabela 1, que apresenta os índices de: quantidade de colaboradores e absenteísmo expressa por meio da medida de tendência central média; turnover, afastamentos do trabalho e produtividade expressas como resultado total anual de acordo com o período analisado.

Observando os dados referentes ao número de colaboradores, percebe-se aumento anual gradativo. Quanto à produtividade, também constata-se aumento do primeiro para o segundo ano, porém houve redução no terceiro ano devido ao rompimento de uma grande parceria de vendas da empresa. A produção voltou a aumentar no quarto ano, o de maior produtividade no período analisado.

Com relação às médias de absenteísmo por ano, percebe-se um pequeno aumento deste indicativo no segundo ano analisado, que se reduziu singelamente no terceiro ano e ainda mais no quarto ano. Já em relação ao turnover e aos afastamentos obser- 
Tabela 1 - Caracterização da base de dados da empresa por período

\begin{tabular}{cccccc}
\hline Período & $\begin{array}{c}\text { Média de } \\
\text { colaboradores }\end{array}$ & $\begin{array}{c}\text { Média de } \\
\text { absenteísmo (\%) }\end{array}$ & $\begin{array}{c}\text { Turnover } \\
(\boldsymbol{\%})\end{array}$ & $\begin{array}{c}\text { Afastamento do } \\
\text { trabalho } \\
(\mathbf{\%})\end{array}$ & $\begin{array}{c}\text { Produtividade total } \\
(\mathbf{k g})\end{array}$ \\
\hline Ano 1 & 154 & 10,34 & 13,57 & 1,29 & 10095726,6 \\
Ano 2 & 171 & 11,84 & 21,57 & 2,92 & 11249540,7 \\
Ano 3 & 191 & 11,70 & 23,92 & 3,66 & 10508890,1 \\
Ano 4 & 200 & 10,38 & 15,97 & 2 & 12453380,2 \\
\hline
\end{tabular}

Variáveis categóricas de número de colaboradores e absenteísmo apresentadas em média anual, turnover em porcentagem anual, afastamento do trabalho em $\mathrm{n}(\%)$ e a produtividade total anual expressa em KG.

Fonte: Dados da pesquisa.

va-se aumento dos índices no segundo ano, que continuaram crescendo no terceiro ano, enquanto que no quarto ano apresentaram queda nos percentuais. Considerando que o serviço de ergonomia iniciou-se em janeiro de 2017 (metade do Ano 2), observa-se que a ergonomia pode ter auxiliado na redução destes indicadores mesmo com o aumento da produtividade do terceiro para o quarto ano, chegando no maior índice de produtividade que a empresa já alcançou até o presente momento.

Na Figura 1 pode-se observar a relação entre os índices de média anual de absenteísmo, turnover anual total e produtividade anual em quilogramas. Não se observa nenhuma relação entre as variáveis, uma vez que apresentam comportamento variável.

A análise estatística não apresentou diferença significativa da redução dos índices de absenteísmo $(p=0,30)$, turnover $(p=0,944)$ e afastamentos do trabaIho $(p=0,514)$ no período pré e pós instituição do serviço de ergonomia (Tabela 2). Salienta-se, porém, que neste caso o não aumento de absenteísmo, turnover e afastamento do trabalho são resultados positivos, considerando que aumentou o número de funcionários e também a produtividade da empresa.

Tabela 2 - Análise estatística de comparação do banco de dados da empresa

\begin{tabular}{cc}
\hline Variáveis & Resultado (p) \\
\hline Absenteísmo x Ano & 0,309 \\
Turnover x Ano & 0,944 \\
Afastamento x Ano & 0,514 \\
\hline
\end{tabular}

A variável ano refere-se ao período de tempo de 12 meses. Fonte: Dados da pesquisa.

Para melhor compreender os motivos do absenteísmo, a Tabela 3 apresenta uma relação em porcentagem das horas de produção perdidas, ou seja, horas em que o trabalhador não estava presente no trabaIho. Este déficit de horas foi analisado de acordo com categorias apresentadas pelo colaborador para justificar sua ausência. Entre as categorias encontra-se: "Atestado Médico - Dias" e "Falta Justificada - Dias", que se referem a atestados médicos ou faltas justificadas apresentadas pelos colaboradores nas quais estes

Figura 1 - Relação de turnover, absenteísmo e produtividade por período analisado

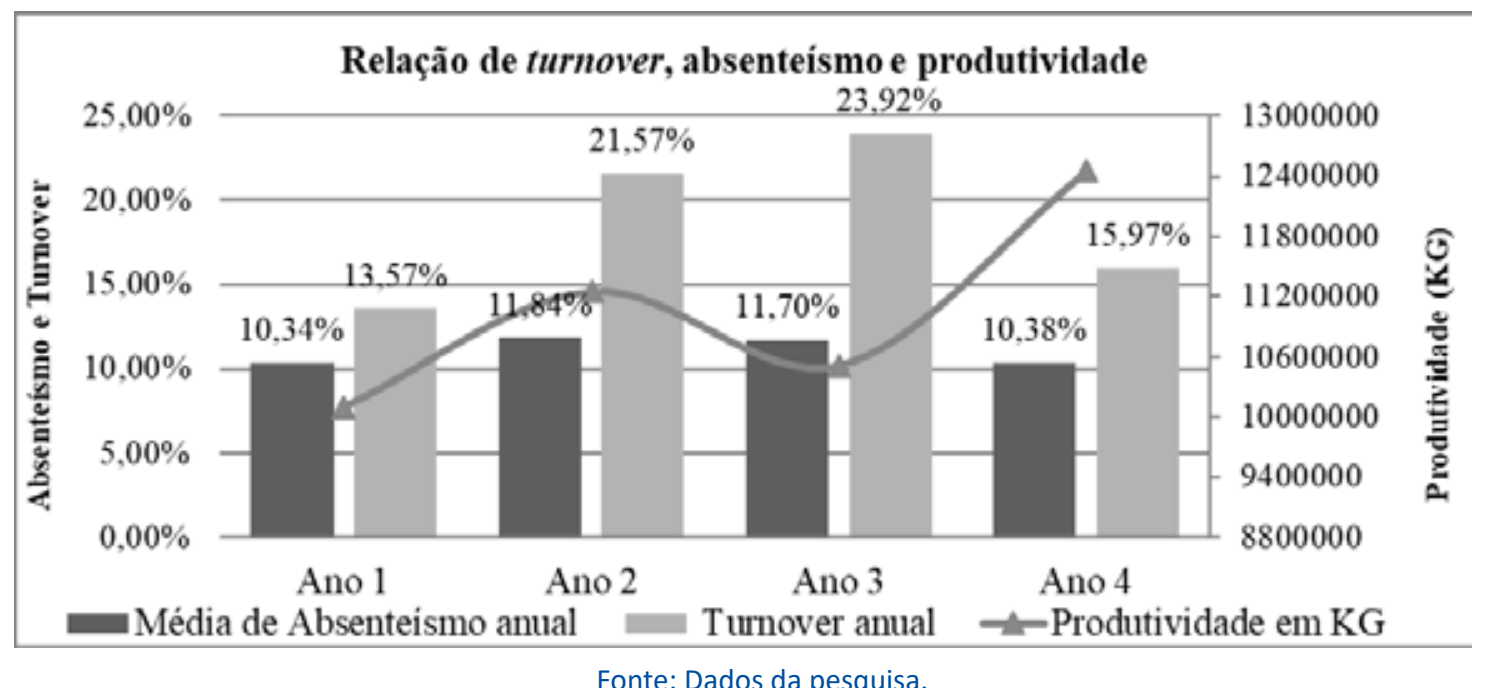

Fonte: Dados da pesquisa. 
permanecem um ou mais dias afastados de suas atividades; "Atestado Médico - Faixa de Horas" e "Falta Justificada - Faixa de Horas", que se referem a atestados ou faltas justificadas apresentadas pelos colaboradores, nas quais os mesmos permanecem por uma faixa determinada de horas afastados da empresa. Para elaborar esta tabela calcularam-se os dias úteis de cada ano, transformando-os em horas trabalhadas por dia e multiplicando pelo número médio de colaboradores do respectivo período, sendo o resultado deste cálculo referente a $100 \%$ de horas anuais contratadas pela empresa. Posteriormente calculou-se a quantidade de horas em que os trabalhadores não estiveram em seu local de trabalho, para assim identificar a porcentagem de horas perdidas por período.
Quando se transforma o absenteísmo em dias perdidos, apresenta-se a Figura 2 que representa a relação de dias em que o colaborador esteve fora de suas atividades laborais em decorrência de atestados médicos ou faltas justificadas (dias ou faixa de horas). Para a sua formulação seguiu-se os mesmos passos dos cálculos e categorias da Tabela 2, porém seu resultado está expresso em dias, ou seja, representa a quantidade de dias por período em que o trabalhador não estava trabalhando, logo não estava produzindo.

Ao analisar a Tabela 3 e a Figura 2 pode-se observar que o Ano 1 apresentou perda de 0,79\% das horas totais de trabalho, o que equivale a 308 dias a menos de produção. O Ano 2 apresentou um aumento da perda de horas para $0,90 \%$ das horas trabalhadas, que equivale a 399 dias perdidos. Já no ano 3

Tabela 3 - Relação de horas de trabalho perdidas - porcentagem

\begin{tabular}{cccccc}
\hline Período & $\begin{array}{c}\text { Atestado médico } \\
\text { - Dias (\%) }\end{array}$ & $\begin{array}{c}\text { Atestado médico - } \\
\text { Faixa de horas (\%) }\end{array}$ & $\begin{array}{c}\text { Falta justificada - } \\
\text { Dias (\%) }\end{array}$ & $\begin{array}{c}\text { Falta justificada } \\
\text {-Faixa de horas (\%) }\end{array}$ & Total (\%) \\
\hline Ano 1 & 0,65 & 0,02 & 0,04 & 0,03 & 0,74 \\
Ano 2 & 0,84 & 0,02 & 0,03 & 0,01 & 0,90 \\
Ano 3 & 0,56 & 0,02 & 0,05 & 0,01 & 0,64 \\
Ano 4 & 0,68 & 0,03 & 0,06 & 0,02 & 0,79 \\
\hline
\end{tabular}

Fonte: Dados da pesquisa.

Figura 2 - Relação de dias de trabalho perdidos

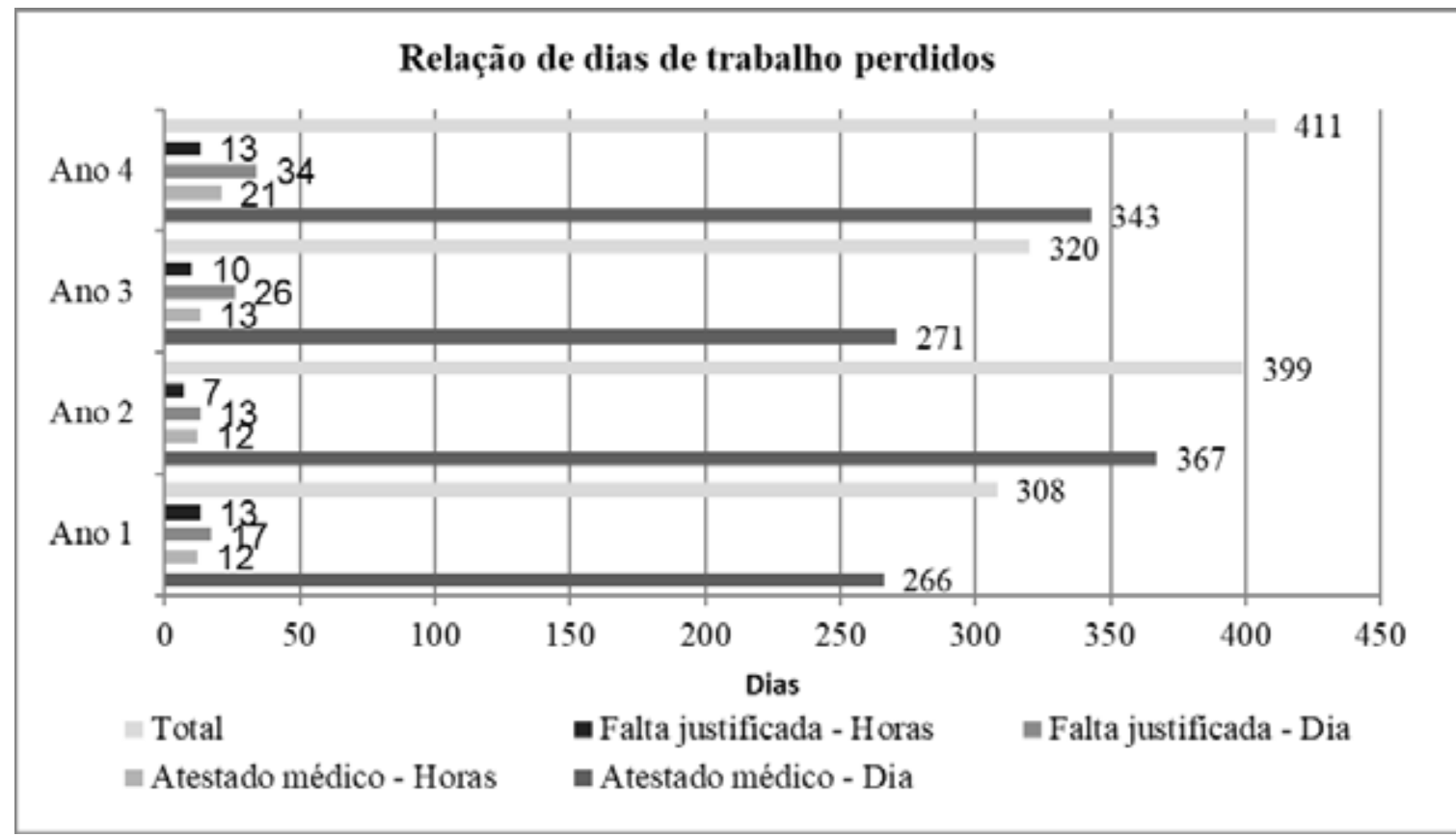

Fonte: Dados da pesquisa. 
ocorreu queda nos percentuais para $0,64 \%$, sendo a taxa mais baixa de todos os períodos avaliados, equivalente a 320 dias perdidos. Por fim o Ano 4 elevou as horas perdidas novamente para $0,79 \%$, que equivale a 411 dias de produção perdidos. Ainda se observa que a maior parte das faltas foram justificadas por atestados médicos equivalentes a dias, seguidos de faltas justificadas também referentes a dias.

\section{Análise do questionário}

A análise qualitativa do serviço de ergonomia prestado na empresa ocorreu por meio da aplicação de um questionário, elaborado com questões abertas e fechadas. A população que aceitou participar do estudo (129 indivíduos) caracteriza-se conforme descrito na Tabela 4, sendo a maioria do sexo masculino, divididos entre as categorias de colaboradores da produção $(89,9 \%)$, encarregados $(4,6 \%)$ e proprietários/ gestores $(5,4 \%)$, com mediana de 60 meses de empresa ( 5 anos) e mediana de 36 meses de atuação no setor atual (3 anos).

Tabela 4 - Caracterização amostral referente ao sexo, à mediana de tempo de empresa (meses) e à hierarquia da empresa

\begin{tabular}{lc}
\hline \multicolumn{1}{c}{ Variáveis } & $\mathbf{n = 1 2 9}$ \\
\hline Sexo - n (\%) & $98(76,0)$ \\
$\quad$ Sexo masculino & $31(24,0)$ \\
$\quad$ Sexo feminino & \\
Tempo de empresa - mediana (Mínimo/ & $60(24-117)$ \\
Máximo) & $36(18-72)$ \\
Tempo total, meses & \\
Tempo no setor atual, meses & $116(89,92)$ \\
Hierarquia da empresa - n (\%) & $6(4,65)$ \\
Colaboradores da produção & $7(5,43)$ \\
Encarregados de setor & \\
Proprietários &
\end{tabular}

Fonte: Dados da pesquisa.

Quando os colaboradores da produção foram questionados sobre o que, na sua percepção, seria a ergonomia, 58,6\% afirmaram não saber defini-la. Já dos 33,6\% que a definiram, 40,5\% associaram a ergonomia com sua saúde e/ou a postura no trabalho. Entre elas, algumas respostas foram mais complexas, por exemplo: "Ergonomia é trabalhar com o mínimo de esforço e máximo conforto", ou ainda, "É um meio de análise das melhorias das condições de trabalho, evitando patologias e proporcionando a segurança". Além disso, embora a maior parte dos colaboradores não soubesse definir a ergonomia, 84,5\% deles foram capazes de perceber a importância dela na empresa e justificá-la. Entre as justificativas expostas pelos co- laboradores, algumas se destacam: "Porque trabalhamos várias horas, e isso é forçado para o corpo. Todos os dias mesma rotina e mesmo trabalho e a ergonomia ajuda a reduzir isso" e "Porque com ela o trabalho rende mais sem diminuir a saúde".

Em contraponto, quando os proprietários/gestores da empresa foram questionados sobre a importância do serviço prestado pela ergonomia, 100\% deles a apontaram como importante, e a justificaram de um ponto de vista diferente: "Porque reduziu os índices de acidentes de trabalho nos últimos dois anos, e aumentou o contentamento do colaborador, e assim aumentou também a qualidade do nosso produto", "Porque os funcionários ficam mais na empresa, assim não precisam estar saindo do trabalho" e "Para o bem do trabalhador, e para assim aumentar o rendimento da empresa".

Já entre os encarregados, $100 \%$ julgam a ergonomia importante para a empresa. A justificativa pela qual a consideram importante baseia-se principalmente em adaptações/melhorias do ambiente de trabalho e a saúde do colaborador: "Contribui para o bem-estar dos colaboradores no sentido de melhor adaptar os setores e as funções ao colaborador, bem como diminuir o tempo de afastamento deles por doenças do trabalho".

Desta forma percebe-se a diferença entre o ponto de vista do colaborador, do proprietário/gestor e do encarregado, uma vez que enquanto o primeiro vê como um benefício que facilita de seu trabalho e conserva sua saúde, o segundo pensa no serviço de ergonomia como um instrumento de aumento da produtividade, qualidade do produto e rendimento, e o terceiro percebe como uma mescla entre os dois primeiros.

O estudo abordou também a interação da população com o ergonomista e as melhorias realizadas pelo serviço de ergonomia na empresa. Entre os colaboradores entrevistados 62,1\% afirmaram conhecer o ergonomista da empresa e 39,6\% já o procuraram para solucionar algum problema notado por eles nas dependências da empresa. Dos que o procuraram, 95,6\% tiveram o problema apontado solucionado.

Quanto aos proprietários, todos conhecem o ergonomista, porém somente $71,42 \%$ já o procuraram, e $100 \%$ deles tiveram os problemas percebidos solucionados, inclusive os que não o procuraram diretamente. Considerando os encarregados de setor, $100 \%$ afirmaram conhecer o ergonomista, porém apenas $50 \%$ deles já entraram em contato direto com ele para solucionar algum problema, e destes $66,7 \%$ tiveram o problema solucionado. 
Em relação às mudanças percebidas pelos colaboradores, as mais citadas têm relação com a regulagem das bancadas e o sistema de rodízio de função, como: "Rodízios com os colegas, ajudando nas dores da coluna", "Mesas e plataformas de altura correta". Já os proprietários destacaram adaptações realizadas em seus setores, como a regulagem da altura dos monitores, apoio para os pés e regulagem das cadeiras, porém citaram também uma visão ampla no serviço prestado na empresa: "Melhorias no mobiliário, adequação do trabalho às gestantes e mudanças no fluxograma da empresa em relação à produção e à ergonomia".

Ainda em relação às melhorias ergonômicas percebidas, outra benfeitoria muito citada por toda a hierarquia é o atendimento fisioterapêutico dentro da unidade fabril, voltado aos seus colaboradores mediante uma parceria com uma Instituição de Ensino Superior, que visa a atuar preventivamente em todo e qualquer aspecto relacionado à saúde do colaborador. Estes atendimentos são realizados por estagiários sob a supervisão de um professor.

Os colaboradores ainda foram questionados quanto a sua percepção de segurança e valorização após o serviço de ergonomia: $63,79 \%$ sentem-se mais seguros e $71,55 \%$ mais valorizados após o início do serviço de ergonomia na empresa. Entre os encarregados, $66,66 \%$ sentem-se mais seguros e $83,33 \%$ mais valorizados. Já entre os proprietários $100 \%$ deles sentem-se mais seguros e valorizados.

Quanto às sugestões de melhoria para o setor de ergonomia, a grande maioria respondeu que o serviço já estava bom e que deveria continuar trazendo melhorias à empresa, porém uma declaração de um proprietário se destacou: "Lembrar que se trata de uma empresa privada, e que também deve-se pensar no fluxograma da empresa e no lucro", referindo-se ao fato de que o ergonomista deve realizar as adaptações de acordo com a condição financeira da empresa e buscar sempre estratégias que aumentem a produtividade do colaborador. Já os colaboradores relataram que algumas bancadas ainda não possuem regulagem de altura, e que isto dificulta o sistema de rodízio, uma vez que ela não se adapta a todos os funcionários.

A análise estatística da comparação das variáveis questionadas aos colaboradores está representada na Tabela 5. Ela indica que não há significância entre as variáveis "hierarquia da empresa" e a opinião sobre a "importância do serviço de ergonomia" $(p=0,508)$, compreendendo-se então que a opinião sobre a importância da ergonomia independe da hierarquia do entrevistado. $\mathrm{O}$ mesmo ocorre quando se compara o tempo que o entrevistado é funcionário da empresa com a sua opinião sobre a importância do serviço de ergonomia $(p=0,176)$, ou seja, sua opinião sobre a importância da ergonomia é independente do tempo que o funcionário é colaborador da empresa. Estes resultados podem estar associados ao fato de a ergonomia atuar fortemente, quinzenalmente em todos os períodos de ingresso da empresa (funcionários em treinamento até de longa data de colaboração) e os mais variáveis níveis de hierarquias.

Quando foram comparadas as variáveis "importância da ergonomia" com a sensação dos entrevistados sobre valorização e segurança, obteve-se valor significativo ( $p=0,001$ e $p=0,000$, respectivamente), ou seja, os colaboradores que consideram a ergonomia importante na empresa também se sentem mais valorizados e seguros após o início deste serviço. Em relação à interação dos entrevistados com o ergonomista da empresa, o resultado é significativo entre a comparação da procura do profissional para solucionar algum problema e a sua solução $(p=0,000)$. Assim, quase a totalidade dos entrevistados que procuraram o ergonomista para solucionar um problema tiveram este solucionado.

Do mesmo modo, quando se compara a variável "identificação de uma mudança/adaptação" com a variável "facilitou o seu trabalho?" e "facilitou o trabaIho de seu colega?", obteve-se resultado significante ( $p=0,000$ e $p=0,000$, respectivamente), indicando que os colaboradores que perceberam as adaptações realizadas na empresa consideram que elas facilitaram o seu trabalho e/ou de seu colega. A comparação entre a "identificação de mudanças/adaptações" agora relacionadas à sensação de os entrevistados sentirem-se "valorizados" e "seguros" também obteve resultado significativo ( $p=0,000$ e $p=0,000$, respectivamente), com isso podendo-se afirmar que o colaborador que identifica as mudanças realizadas pela ergonomia sente-se mais valorizado e seguro na empresa.

\section{DISCUSSÃO}

Este estudo não apresentou diferença significativa da redução dos índices de absenteísmo, turnover e afastamentos do trabalho no período pré e pós-instituição do serviço de ergonomia, porém os resultados são considerados positivos, devido ao aumento do número de funcionários e também à produtividade da empresa, pois o absenteísmo é um fator que afeta a empresa em diversos pontos, tanto na questão financeira, devido ao trabalhador deixar de produzir, elevando o custo operacional, quanto na questão humana (SOARES, 2013). No Brasil ainda faltam estudos 
Tabela 5 - Análise estatística de comparação

das variáveis segundo a percepção do trabalhador referente ao serviço de ergonomia

\begin{tabular}{|c|c|}
\hline Variáveis & Resultado (p) \\
\hline Hierarquia x Você considera o serviço de ergonomia necessário na empresa? & 0,508 \\
\hline Tempo de empresa x Você acha o serviço de ergonomia necessário na empresa? & 0,176 \\
\hline $\begin{array}{l}\text { Você acha o serviço de ergonomia necessário na empresa? x Você se sente mais valorizado devido } \\
\text { ao serviço de ergonomia? }\end{array}$ & 0,001 \\
\hline $\begin{array}{l}\text { Você acha o serviço de ergonomia necessário na empresa? x Você se sente mais seguro devido ao } \\
\text { serviço de ergonomia? }\end{array}$ & $\leqq 0,001$ \\
\hline Você já procurou o ergonomista para solucionar algum problema? x O problema foi solucionado? & $\leq 0,001$ \\
\hline $\begin{array}{l}\text { Você notou alguma mudança/adaptação realizada pela ergonomia? x Esta mudança/adaptação } \\
\text { facilitou o seu trabalho? }\end{array}$ & $\leqq 0,001$ \\
\hline $\begin{array}{l}\text { Você notou alguma mudança/adaptação realizada pela ergonomia? x Esta mudança/adaptação } \\
\text { facilitou o trabalho de seu colega? }\end{array}$ & $\leqq 0,001$ \\
\hline $\begin{array}{l}\text { Você notou alguma mudança/adaptação realizada pela ergonomia? x Você se sente mais seguro } \\
\text { devido ao serviço de ergonomia? }\end{array}$ & $\leqq 0,001$ \\
\hline $\begin{array}{l}\text { Você notou alguma mudança/adaptação realizada pela ergonomia? x Você se sente mais valorizado } \\
\text { devido ao serviço de ergonomia? }\end{array}$ & $\leq 0,001$ \\
\hline
\end{tabular}

Fonte: Dados da pesquisa.

que quantifiquem os prejuízos financeiros causados pelo absenteísmo (SANTIAGO, 2017). Entre os motivos do absenteísmo, aqueles por doenças são mais frequentes, ou seja, a ausência do trabalhador mediante atestado médico corresponde à maior parte dos registros de absenteísmo (PEREIRA, 2019) corroborando os achados do presente estudo.

O absenteísmo ainda pode ser classificado em tipo I e tipo II. O primeiro refere-se à perda de produção por horas não trabalhadas e o segundo é referente a quando o trabalhador, mesmo sem faltar, não atinge seu desempenho máximo, também reduzindo a produtividade (COBÊRO; LIMA, 2019). Borchardt (2018) analisou o absenteísmo tipo I em um frigorífico e apontou os atestados médicos como a principal causa de absenteísmo. Tentando quantificar os dias perdidos no absenteísmo tipo I, Heemann (2013) o estudou em um frigorífico com mais de 700 colaboradores e constatou que os atestados médicos foram responsáveis por 8.670 dias de trabalho perdidos no ano de 2012, constituindo o maior motivo de falta. Comparando estes estudos ao presente trabalho evidencia-se que ambos obtiveram predomínio de absenteísmo devido a atestados médicos, porém quando abordada a quantidade de dias perdidos por ano, este estudo apresentou números consideravelmente menores, mesmo que comparando o número de trabalhadores envolvidos (266 dias perdidos no Ano 1 com 154 colaboradores, 367 dias no Ano 2 com 171 colaboradores,
271 dias no Ano 3 com 191 colaboradores, e 343 dias perdidos de trabalho no Ano 4 com 200 colaboradores).

Já o turnover ou rotatividade é definido pela flutuação de trabalhadores, ou seja, é constituído mediante a relação entre contratações e demissões. É resultante de fenômenos organizacionais internos ou externos, que resultam em aumento de custo, redução da produtividade e de capital empresarial (ABREU, 2015). Campos e Malik (2008) utilizaram como classificação do índice de turnover de médicos generalistas de um Programa de Saúde da Família (PSF) de São Paulo os seguintes valores: de $0 \%$ a $25 \%$ de turnover ao ano representa rotatividade adequada; de $25 \%$ a $50 \%$ ao ano é considerado ruim; acima de $50 \%$ ao ano é visto como crítico. Os autores ainda afirmam que a rotatividade, quando acima de $26 \%$ por ano, produz altos impactos financeiros, enquanto que acima de $50 \%$ ao ano já há o risco de comprometer a produtividade e a qualidade do produto. Considerando esta classificação, este estudo apresentou rotatividade adequada em todos os anos analisados, o que evitou maiores impactos financeiros para a empresa.

Maia e Lubaski (2015) avaliaram a relação do absenteísmo e do turnover com a produtividade de quatro empresas. Para a relação de absenteísmo com produtividade, duas empresas não apresentaram relação identificável, porém as outras duas mostraram comportamento diferente, em que nos períodos de 
pico de absenteísmo a produtividade diminuía. Já ao relacionar o turnover com a produtividade, três empresas apresentavam baixa produtividade quando os níveis de turnover estavam elevados, e uma delas não apresentou relação. Ainda sobre a produtividade, Santana (2002) realizou um estudo sobre a aplicabilidade da ergonomia na melhora da produtividade e a sua relação com as condições de trabalho, chegando à conclusão de que a ergonomia pode contribuir para o enriquecimento dos métodos de produtividade, uma vez que a análise ergonômica do trabalho possibilitou a compreensão do sistema de trabalho e auxiliou nas soluções para os problemas apresentados. O presente estudo não foi capaz de analisar a significância do aumento da produtividade na empresa estudada, devido ao fato de não termos acesso a informações referentes à produtividade de cada trabalhador individualmente, tendo apenas relatórios da produtividade geral mensal em quilogramas.

Os afastamentos do trabalho são caracterizados por atestados médicos que ultrapassem 15 dias, ou seja, no décimo sexto dia de atestado a empresa deve encaminhar o colaborador à Previdência Social, que arcará com as despesas a partir de então, por meio de benefícios como uma licença para tratar de sua condição de saúde (HEEMANN, 2013). Ao avaliar os afastamentos de trabalho em um frigorífico durante o período de um ano, Heemann (2013) constatou o número de 107 colaboradores afastados, o que no caso em questão correspondeu a aproximadamente $15 \%$ da média mensal de colaboradores da empresa, divergindo dos resultados apresentados neste estudo, que ao analisar o Ano 1 constata 2 afastamentos, correspondendo a $1,29 \%$ da média anual de colaboradores, no Ano 2 houve 5 afastamentos, correspondendo a 2,92\% da média anual de colaboradores, no Ano 3 houve 7 afastamentos, o que corresponde a 3,66\% da média anual de colaboradores, e o Ano 4 apresentou 4 afastamentos, correspondendo a $2 \%$ da média anual de colaboradores.

As adaptações ergonômicas podem ter influenciado nestes indicadores, uma vez que elas conseguem reduzir o estresse e desconforto no trabalho e eliminar inúmeros riscos à saúde dos trabalhadores (NASCIMENTO et al., 2019). Esse fato foi evidenciado neste estudo por meio do questionário, que também identificou a presença da ergonomia participativa dentro da empresa, uma vez que os trabalhadores possuem controle para analisar e identificar fatores de riscos ergonômicos, participando do projeto e instituição das soluções ergonômicas (BONFANTTI; VASCONCELLOS; FERREIRA, 2017), mostrando-se inevitável o contato com o ergonomista e a construção da ergonomia dentro da empresa (RODRIGUES, 2018). Souza et al. (2019) citam que um dos melhores aspectos das abordagens participativas é a adaptabilidade ao contexto e necessidades do ambiente laboral, tarefas de trabalho e trabalhadores.

Indo ao encontro destas afirmações, este estudo optou por avaliar o serviço de ergonomia pela perspectiva dos colaboradores e proprietários/gestores utilizando entrevistas em forma de questionário, buscando identificar riscos, buscar soluções e também avaliar a percepção e conhecimento da hierarquia sobre o serviço prestado. A escolha desta ferramenta seguiu a indicação de Ferreira, Merino e Figueiredo (2017), que definem as entrevistas como ferramentas de baixo custo e rápida aplicação, que proporcionam dados passíveis de serem aproveitados pelo ergonomista tanto para sugestões de melhorias quanto como instrumento de comparação de situações antecedentes e posteriores à ergonomia.

Considerando a caracterização amostral, Mariz (2011), por meio de questionários aplicados em um frigorífico, constatou que a maior parte dos colaboradores entrevistados é do sexo masculino (66\%), assemelhando-se a este estudo (76\%). Em relação ao tempo de empresa Simões e Rocha (2014), ao avaliarem o absenteísmo de uma empresa florestal, encontraram mediana de 15 meses ( 1 ano e 3 meses), com variação entre 3 meses e 27 anos nesta variável, distanciando-se deste estudo, que identificou mediana de 60 meses ( 5 anos) com variação entre 24 e 117 meses para tempo total na empresa e mediana de 36 meses ( 3 anos), com variação de 18 a 72 meses para o tempo em que o colaborador se encontra no setor atual.

Fatores que podem estar influenciando na maior permanência de tempo dentro da empresa é a busca por melhoria contínua dentro da unidade fabril. Para saber o que deve ser melhorado, assim como Ribeiro (2017), este estudo buscou coletar informações sobre as dificuldades encontradas pelos trabalhadores na realização das atividades laborais e após análise do questionário obteve informações sobre os principais problemas identificados, assim como alternativas para adaptá-los. E também identificou que segundo os trabalhadores as mudanças já realizadas surtiram efeito, facilitando o trabalho do entrevistado $(62,8 \%)$ ou de algum colega $(61,2 \%)$.

Essa atitude impacta positivamente na satisfação do trabalhador referente ao seu ambiente laboral. Sabendo da importância de ter um trabalhador satisfeito, estudos veem apontando e definindo a satisfação no trabalho como um estado emocional de prazer 
e positividade em resultado à avaliação do trabalho dos colaboradores ou de suas experiências no ambiente laboral (RIBEIRO, 2017).

Os questionários sobre satisfação no trabalho no ramo frigorífico já foram utilizados anteriormente por Carrer et al. (2018) em empresa com 249 colaboradores. O questionário apresentava perguntas sobre a convivência com chefes, salário, confiança, orgulho, etc. Concluíram que a maior parte dos colaboradores sente orgulho de trabalhar na empresa e percebem a sua importância dentro dela. De maneira semelhante, este estudo avaliou por meio de questionamentos a percepção de valorização e segurança dos colaboradores após o início do serviço de ergonomia na empresa. Assim como no estudo de Carrer et al. (2018), observou-se que a maior parte dos colaboradores apresenta contentamento positivo nos pontos avaliados, destacando-se que $65,9 \%$ sentem-se mais seguros e $72,1 \%$ mais valorizados após o início do serviço de ergonomia.

Além disso, a satisfação também é apontada pela literatura como um determinante do absenteísmo e do turnover, podendo aumentar os dados referentes à hipótese de a ergonomia ter impactado positivamente nos indicadores em questão neste estudo. Santiago (2017) realizou uma pesquisa bibliográfica com o objetivo de identificar as principais estratégias para o controle do absenteísmo no Brasil, concluindo que de forma geral as medidas relatadas pelos estudos eram baseadas no aumento da motivação do trabalhador em suas atividades laborais, enquanto Nodari, Dal Bó e Camargo (2010) relacionam a satisfação profissional com os índices de turnover, em que os colaboradores apresentaram uma satisfação parcial em suas atividades laborais, e acreditam que este fator é a causa principal dos altos índices de turnover. A produtividade também pode ser impactada pela satisfação do trabalhador, pois a motivação o leva a ser mais persistente e esforçar-se mais, consequentemente aumentaria sua eficiência na produção (CARRER et al., 2018).

\section{CONCLUSÃO}

Conclui-se que mesmo com os resultados estatisticamente não significantes na comparação do período pré e pós-início do serviço de ergonomia no que se refere ao absenteísmo, turnover e afastamento do trabalho, pode-se notar que os índices não aumentam, mesmo com o aumento de produtividade e número de trabalhadores, demonstrando que a ergonomia pode ser uma ferramenta positiva para a empresa. Identificou-se também que apesar de dife- rentes percepções sobre a ergonomia, independentemente da hierarquia na empresa a opinião sobre a importância e necessidade do serviço de ergonomia é a mesma, influenciando no sentimento de segurança e valorização do trabalhador.

Entre os benefícios deste estudo para a amostra em questão aponta-se que poderão ser realizadas novas adaptações na empresa, a partir das sugestões de melhorias apresentadas nos questionários. Também será possível realizar reuniões internas que busquem alternativas para melhorar os indicadores detalhados neste trabalho.

Entre as limitações desta pesquisa aponta-se o número amostral não atingido e que não foi possível elaborar um relatório de produtividade individual, pois a mesma peça passa por vários setores, do abate até a expedição, dificultando a análise estatística. Sugere-se novos estudos com maior número amostral, além de uma análise detalhada sobre as causas do absenteísmo, para melhor identificar a relação entre a ergonomia e os índices de absenteísmo.

\section{REFERÊNCIAS}

ABREU, S. A. Determinação dos sinais e sintomas da síndrome de Burnout através dos profissionais da saúde da Santa Casa de Caridade de Alfenas Nossa Senhora do Perpétuo Socorro. Revista da Universidade Vale do Rio Verde, v. 13, n. 1, p. 204-238, 2015.

BAIXINHO, C. L. et al. Prevenção de lesões músculo esqueléticas: relatos dos enfermeiros especialistas em saúde materna e obstetrícia. Atas CIAIQ, 2, p. 488-497, 2016.

BONFANTTI, R. J.; VASCONCELLOS, L. C. F.; FERREIRA, A. P. Ergonomia, desenvolvimento e trabalho sustentável: um olhar para a saúde do trabalhador. Revista Brasileira de Medicina do Trabalho, v. 15, n. 3, p. 257-266, 2017.

BORCHARDT, G. M. Absenteísmo no ramo frigorífico: um estudo de caso no frigorífico Globoaves no município de Espigão do Oeste-RO. 2018. Trabalho (Conclusão de Curso) Fundação Universidade Federal de Rondônia, Cacoal, 2018.

CAMPOS, C. V. A.; MALIK, A. M. Satisfação no trabalho e rotatividade dos médicos do programa de saúde da família. Rev. Adm. Pública, 42(2), p. 347-368, 2008.

CARRER, M. L. F. et al. Satisfação no trabalho em um setor frigorífico da serra gaúcha. In: XVIII MOSTRA DE INICIAÇÃO CIENTíFICA, 18., Pós-Graduação, Pesquisa e Extensão - UCS. Caxias do Sul: Universidade de Caxias do Sul, 2018.

CARVALHO, D. et al. Síndrome de Burnout em profissionais da área da saúde atuantes em dois municípios do interior de Minas Gerais - Brasil. Revista Contexto \& Saúde, 16(31), p. 139-148, 2016. Disponível em: https://doi. org/10.21527/2176-7114.2016.31.139-148. 
COBÊRO, C.; LIMA, C. Análise das causas do absenteísmo em uma distribuidora de alimentos. Revista Científica E-Locução, 1(14), 18, 2019. Disponível em: http://periodicos. faex.edu.br/index.php/e-Locucao/article/view/35.

FERREIRA, A. S.; MERINO, E. A. D.; FIGUEIREDO, L. F. G. Métodos utilizados na ergonomia organizacional: revisão da literatura. Human Factors in Design, 6(12), p. 58-78, 2017.

HEEMANN, S. Agravos à saúde e doenças ocupacionais nos trabalhadores do matadouro-frigorífico de aves de um município do Rio Grande do Sul no ano de 2012. 2013. Trabalho (Conclusão de Curso) - Universidade Federal do Rio Grande do Sul, Porto Alegre, 2013.

HURTADO, L. D. B.; VÉRAS, P. A. F. A fisioterapia na ergonomia e suas repercussões na qualidade de vida do trabalhador. 2015. Trabalho (Conclusão de Curso) - Faculdade São Lucas, Porto Velho, 2015.

MAIA, B. I.; LUBASKI, D. T. C. Análise da interferência do treinamento, do Turnover e do absenteísmo operacional na produtividade industrial. Rev. de Extensão e Iniciação Científica, Unisociesc, 2(2), 2015.

MARIZ, L. F. A qualidade de vida no trabalho na percepção dos colaboradores em um frigorífico. 2011. Monografia Universidade de Brasília, Brasília, 2011.

MTE. Ministério do Trabalho e Emprego. Norma regulamentadora $n^{\circ} 17$ (NR17): ergonomia. Brasília, 1978.

MTE. Ministério do Trabalho e Emprego. Norma regulamentadora $n^{\circ} 36$ (NR36): segurança e saúde no trabalho em empresas de abate e processamento de carnes e derivados. Brasília, 2013.

NASCIMENTO, T. R. L. et al. Ergonomia: saúde ocupacional e qualidade de vida. Revista da Associação Brasileira de Ergonomia, v. 13, n. 1, 2019.

NODARI, C. H.; DAL BÓ, G.; CAMARGO. M. E. Turnover e satisfação no trabalho em uma empresa multinacional: um estudo de caso. Rev. de Adm. da Unimep, Caxias do Sul, v. 8, n. 2, p. 1-16, 2010.

PEREIRA, L. B. P. Absenteísmo por saúde: uma experiência em uma empresa pública mineira. 2019. Monografia (de Especialização). Fundação João Pinheiro - Escola de Governo Professor Paulo Neves de Carvalho. Belo Horizonte, 2019.

RIBEIRO, A. C. F. Aplicação da ergonomia participativa para o projeto do espaço de trabalho de uma empresa de confecção de roupas de Santa Catarina. 2017. Trabalho (Conclusão de Curso) - Universidade Federal de Santa Catarina, Florianópolis, 2017.

RIBEIRO, M. O. Contributos da NR 36 para melhorias das condições de trabalho no frigorífico: o caso do abate e processamento de carne suína. 2017. Dissertação (Mestrado) - Universidade Federal de Santa Catarina, Florianópolis, 2017.

RIGOTTO, R. Desvelando as tramas entre saúde, trabalho e ambiente nos conflitos ambientais: aportes epistemológicos, teóricos e metodológicos. In: RIGOTTO, Raquel. Tramas para a justiça ambiental: diálogo de saberes e práxis emancipatórias. Fortaleza: Edições UFC, 2018. p. 125.
RODRIGUES, D. M. F. Estudo ergonômico participativo no curtume do Instituto SENAI de Tecnologia do couro e meio ambiente. 2018. Trabalho (Conclusão de Curso) - Universidade do Vale do Rio dos Sinos, São Leopoldo, 2018.

SANTANA, A. M. C. A produtividade em unidade de alimentação e nutrição: aplicabilidade de um sistema de medida e melhoria da produtividade integrando a ergonomia. 2002. Tese (Doutorado) - Universidade Federal de Santa Catarina, Florianópolis, 2002.

SANTIAGO, L. et al. Absenteísmo e doença na equipe de profissionais de enfermagem. Revista Contexto \& Saúde, 17(33), p. 43-57, 2017. Disponível em: https://doi. org/10.21527/2176-7114.2017.33.43-57.

SIMÕES, M. R. L.; ROCHA, A. D. M. Absenteísmo-doença entre trabalhadores de uma empresa florestal no Estado de Minas Gerais, Brasil. Revista Brasileira de Saúde Ocupacional, 39(129), p. 17-25, 2014.

SOARES, M. M. Adequação ergonômica e redução do índice de absenteísmo e afastamento: análise para aumento da capacidade produtiva. 2013. Trabalho (Conclusão de Curso) - Centro Universitário Eurípides de Marília - Univem, Marília, 2013.

SOUZA, D. T. et al. Análise ergonômica do trabalho: adequações do posto de trabalho do borracheiro a partir de uma prática curricular de extensão. Sinapse Múltipla, 8(2), p. 126-131, dez. 2019.

TEIXEIRA, F. C. Gestão de saúde e segurança do trabalho: uma análise a partir da gerência de atenção à saúde do Ministério Público de Santa Catarina. 2017. Trabalho (Conclusão de Curso) - Universidade Federal de Santa Catarina, Departamento de Serviço Social, Centro Socioeconômico. Florianópolis, 2017. 